ORIGINAL ARTICLE

\title{
Identification of descendants of an extinct bovine population from the Algarve region of Portugal using numerical taxonomy analysis of morphological traits
}

\author{
M.F. Sobral ${ }^{1}$, C. Roberto ${ }^{2}$, D. Navas ${ }^{2}$, I. Palmilha ${ }^{3}$, M.B. Lima ${ }^{4}$ \& A. Cravador ${ }^{5,6}$ \\ 1 Direcção Geral de Veterinária-DSPA, Lisboa, Portugal \\ 2 Estação Zootécnica Nacional, Vale de Santarém, Portugal \\ 3 Direcção Regional da Agricultura do Algarve, Faro, Portugal \\ 4 Unidade de Taxonomia Numérica, Estação Agronómica Nacional, Oeiras, Portugal \\ 5 Universidade do Algarve, FERN, Faro, Portugal \\ 6 IBB/CGB-UTAD Apartado 10103, Vila Real, Portugal
}

\section{Keywords}

Algarvia bovine breed; extinct breed; morphological characters; numerical taxonomy.

\section{Correspondence}

A. Cravador, Universidade do Algarve, FERN, Campus de Gambelas, 8005-139 Faro, Portugal.

E-mail: acravad@ualg.pt

Received: 16 April 2008; accepted: 18 October 2008

\begin{abstract}
Summary
The morphology of a sample of four bulls and 43 cows, presumed to be descendants of the extinct cattle breed 'Algarvia' (AG), was used to assign their relationship with animals from other Portuguese autochthonous breeds - Arouquesa (AR), Barrosã (BA), Cachena (CA), Marinhoa (MA), Maronesa (MO), Minhota (MN), Mirandesa (MI), (only bulls), Alentejana (AL), Garvonesa (GA), Mertolenga (ME) and Preta (PR). Standard numerical taxonomic methods were applied to a set of 183 (cows) and 170 (bulls) traits, to derive average pairwise taxonomic distances among the sample of 257 cows and 76 bulls. Distance coefficients (morphological index of distance) ranged from 0.22 to 2.62 (cows) and from 0.49 to 2.13 (bulls). Unweighted pair group method using arithmetic averages (UPGMA)-based phenograms and a principal coordinate analysis showed that bulls were highly clustered and cows showed a tendency to cluster according to their geographical and breed origin. The AG population grouped together with GA, AL, ME and MN breeds in the Red Convex group. The average taxonomic distance among breeds was 1.02, the highest being 1.39 (ME versus BA) and the lowest being 0.64 (MA versus AR). The approach allowed for the identification of a phenotypically differentiated set of animals, comprising 19 cows and four bulls representative of the AG breed, and which can be targeted in further studies aiming at the recovery of this extinct breed.
\end{abstract}

\section{Introduction}

In the western part of Iberian Peninsula, Portugal occupies a small geographical area but harbours a considerable diversity of livestock breeds, including some 13 autochthonous breeds (Matos, 2000). A few years ago, the Regional Agricultural Authorities were criticized for their negligence to preserve a native cattle breed from Algarve. The supposed negligence of the Regional Agricultural Authorities in failing to preserve a native cattle breed 'Algarvia' (AG) has provoked some controversy as to the existence of such a cattle population.

The cattle population in the Algarve was first described in 1868, and its morphological attributes have been detailed by various authors (Lima, 1873; 
Nogueira, 1900; Lima, 1919; Vale, 1949; Pereira, 1960; Cordeiro, 1986). On the basis of morphology, the population has been classed in the Aquitanian trunk (Vale, 1949), which, with the Alentejana (AL) and Mertolenga (ME) breeds, forms the Red Convex group dispersed throughout the southern part of Portugal. The animals are predominantly exploited for meat production, as a source of manure and for draught. Although never formally registered in a herdbook as an independent breed, 25000 to 29000 AG individuals were catalogued in the period 1940 to 1970 (Rosado et al, 1981). Numbers have since this time been in rapid decline and the AG breed was considered to be extinct by the 1980s (FAO, 2000). Nevertheless, traditional breeders have repeatedly claimed that animals with the morphological traits of the AG breed can still be found in farms in the region. These reports outline traits consistent with the description by Pereira (1960) and were used for the identification of animals with AG ancestry.

Sobral et al. (2001) have used numerical taxonomy to characterize eight autochthonous Portuguese cattle breeds with 135 morphological traits. As this approach allowed a clustering into definable breeds, we have used the same strategy to characterize animals with claimed AG ancestry. In this way, we have sought to differentiate this group of animals from those belonging to other native breeds, and to identify which individuals could form a suitable nucleus of progenitors for a programme aimed at the recovery of the extinct AG breed.

\section{Material and methods}

Animals

The analysis covered a sample of 257 cows and 76 bulls. Of the former, 47 were AL, 34 were Garvonesa (GA), 102 were ME and 31 were Preta (PR); and of the latter, seven were AL, six GA, six ME, seven PR, six Arouquesa (AR), eight Barrosã (BA), four Cachena (CA), six Marinhoa (MA), seven Maronesa (MO), five Minhota $(\mathrm{MN})$ and 10 Mirandesa (MI). The remaining 43 cows and four bulls, identified with potential AG ancestry, were neither registered nor classified within a breed. They were selected on the basis of morphological traits that are known to correspond to the phenotypic description of the breed in the past, as was attested by traditional breeders. The traits used to identify this group of animals were: medium size (approximately $600 \mathrm{~kg}$ for cows, $800 \mathrm{~kg}$ for bulls) red pelage, long pyramidal head, convex profile, spiralled horns pointing outward, thick neck, large slack dewlap, round wide back, deep breast, long croup, large thigh and rear limb, long tail, udder lighter coloured than the pelage with well-separated teats. The animals were sampled from 95 farms with a geographical spread comprising seven from AL, 10 from GA, 18 from $\mathrm{ME}$, five from $\mathrm{PR}$, six from $\mathrm{AR}$, eight from $\mathrm{BA}$, three from CA, six from MA, seven from MO, five from MN, 10 from $\mathrm{MI}$ and 10 from AG.

\section{Data analysis}

A set of 183 (cows) and 170 (bulls) morphological characters was established from direct and/or photographic observations. Head characters represented $\sim 60 \%$ of these, as they are fairly independent of management and environmental conditions (Alderson, 1992). They included pelage, hair, forehead, profile, muffle, forelock, faces, eyes, eyelids, eyeballs, muzzle, nostril, nose bridge, ears, horns, poll and character states such as size, shape, uniformity, insertion angle, colour, tone, spotted or flecked, profile, tone etc. were evaluated. The remaining $40 \%$ related to the form of the neck, dewlap, brisket, trunk, back, dorsal strip, rump, croup, pin, limbs, testicles, udder, teats, limbs, hoofs and tail. Except for the testicle, crest, udder and teats traits, the same set of characters was evaluated on both sexes.

The derived matrices (characters $\times$ individual animals, or Operational Taxonomic Units, OTUs) were coded (coded numerical values were assigned for every state of each morphological character, e.g. for colour: 1 = red, 2 = black, 3 = brown, 4 = white), standardized by characters and the phenetic relationships among OTUs were calculated by average taxonomic distance coefficients (Sokal, 1961) according to the formula:

$$
d_{j k}=\sqrt{\frac{\sum_{i=1}^{n}\left(x_{i j}-x_{i k}\right)^{2}}{n}}
$$

where $X_{i j}$ and $X_{i k}$ represent the values of the morphological character $i$ in individuals $j$ and $k$, respectively, $n$ the number of valid comparisons between individuals $j$ and $k$, and $d_{j k}$ the distance between $j$ and $k$. A pair of individuals, $j$ and $k$, produced a $d_{j k}=0$ when $j$ and $k$ were considered similar and a $d_{j k}>0$ when they were different.

Three data matrices were generated: matrix $\mathrm{F}$, consisting of 183 morphological characters $\times 257$ cows; matrix $M$ had 170 characters $\times 76$ bulls and matrix $R_{\mathrm{MT}}$ had 170 characters $\times 12$ Portuguese 
autochthonous breeds (each of the 170 characters values represents the mean across all bulls within a breed). The matrices were subjected to standard numerical taxonomic procedures, in which average taxonomic distance coefficients were computed for all pairs of individuals, clustered by the unweighted pair group method using arithmetic averages (UPGMA) algorithm, and the outputs presented as phenograms (Sneath and Sokal, 1973). Cophenetic values were calculated from each phenogram and cophenetic correlation coefficients between the distance matrices and the matrices of the cophenetic values were estimated as a measure of the distortion of the clustering method (Rohlf, 1998). A principal coordinate analysis (Gower, 1966) of the distance matrices was performed, and a projection of the OTUs onto the plane defined by the first and the second principal axes was carried out. Data analysis was performed using NTSYS-pc v2.0 (Rohlf, 1998).

The simultaneous projection of the morphological characters and of animals onto the two principal axes was used to find out which morphological traits are the best in discriminating the AG population.

\section{Results}

\section{Cluster and principal coordinate analyses}

In order to determine whether the candidate AG individuals can be differentiated from the other autochthonous breeds it was first necessary to show that the numerical taxonomic methods based on morphological characters of bulls (Sobral et al., 2001) could be extended to cows because, firstly, bulls have more marked morphological traits than cows; and secondly most of the candidate AG descendants were cows rather than bulls. Southern region breeds belonging to the Red Convex group were chosen for this purpose, as the AG population has been assigned to this group (Vale, 1949). An extended analysis was also performed to include bulls from the twelve native Portuguese breeds in order to allow the inclusion of the four candidate AG bulls in a more complete study.

\section{Cows from the southern region}

The average taxonomic distance coefficients (morphological index of distance) among the 257 cows varied between 0.22 and 2.62. The highest and lowest values between individuals within a breed were AG: 0.40-2.30; AL: 0.46-1.83; GA: 0.66-2.04; ME: 0.22-2.49; PR: 0.39-1.20. Between individuals belonging to different breeds the highest similarity
(0.56) was obtained between an ME and an AL individual, and the lowest (2.62) between an ME and an AG individual.

In the resulting UPGMA-based phenogram (Figure 1) eight groups ( 1 to 8 ) could be recognized although a few of the 257 individuals could not be assigned to one of these groups. All the PR cows clustered within group 4, while groups 1, 3, 7 and 8 contained, respectively, AG, ME-M, ME-R and GA cows. ME-M, refers to a spotted red and white (Malhado) and ME-R to a red speckled (Rosilho or Mil Flores) subtype of ME. Group 5 comprised cows of these two latter subtypes. The remaining groups were heterogeneous with groups 2 and 6 containing AL, GA, AG and ME-U (red uniform) cows.

Principal coordinate analysis was used in order to visualize better the relationships between individuals in a Cartesian space. The first two principal coordinates accounted for $14 \%$ of the variance. The projection of points representing the 257 cows onto the plane defined by the first two axes is presented as Figure 2. Once again, the PR cows were well separated from those of the other breeds, although the clustering in other breeds was weaker. The ME-R subtype was associated with some of the ME-M cows, while ME-U and some GA cows were clustered on the basis of shared pelage colour. GA cows having a lighter coloured head were clustered with some AG, AL and ME-U cows.

\section{Bulls from 12 autochthonous breeds}

The average taxonomic distance coefficients between all pairs of the 76 bulls of the twelve autochthonous breeds varied between 0.49 and 2.13, and their phenetic relationships are shown in Figure 3. Clustering reflected breed identity rather closely. Clusters 1, 2, 3, 4, 5, 6, 7, 8, 9, 10 and 11 represent AL, AG, MN, GA, PR, AR, MA, BA, MO, MI and CA bulls, respectively. AR, MA, BA, MO and MI animals are phenetically close to one another, reflecting the geographical proximity of their region of origin, while AG and GA bulls are split into the two subgroups $2 \mathrm{a} / 2 \mathrm{~b}$ and $4 \mathrm{a} / 4 \mathrm{~b}$. Bulls AG3M and AG4M were sampled from a farm harbouring several AL bulls, and probably therefore descended from $\mathrm{AL} \times \mathrm{AG}$ crosses. GA is a recent breed, previously registered as a sub-type of the AL. Group 12 is heterogeneous, with distinct subtypes within ME defined by their pelage colour. Four bulls remained unassociated with any cluster: MA108M, MI240M, MI235M, GA6M.

The two-dimensional projection (Figure 4) confirmed the strong tendency of the bulls to group 

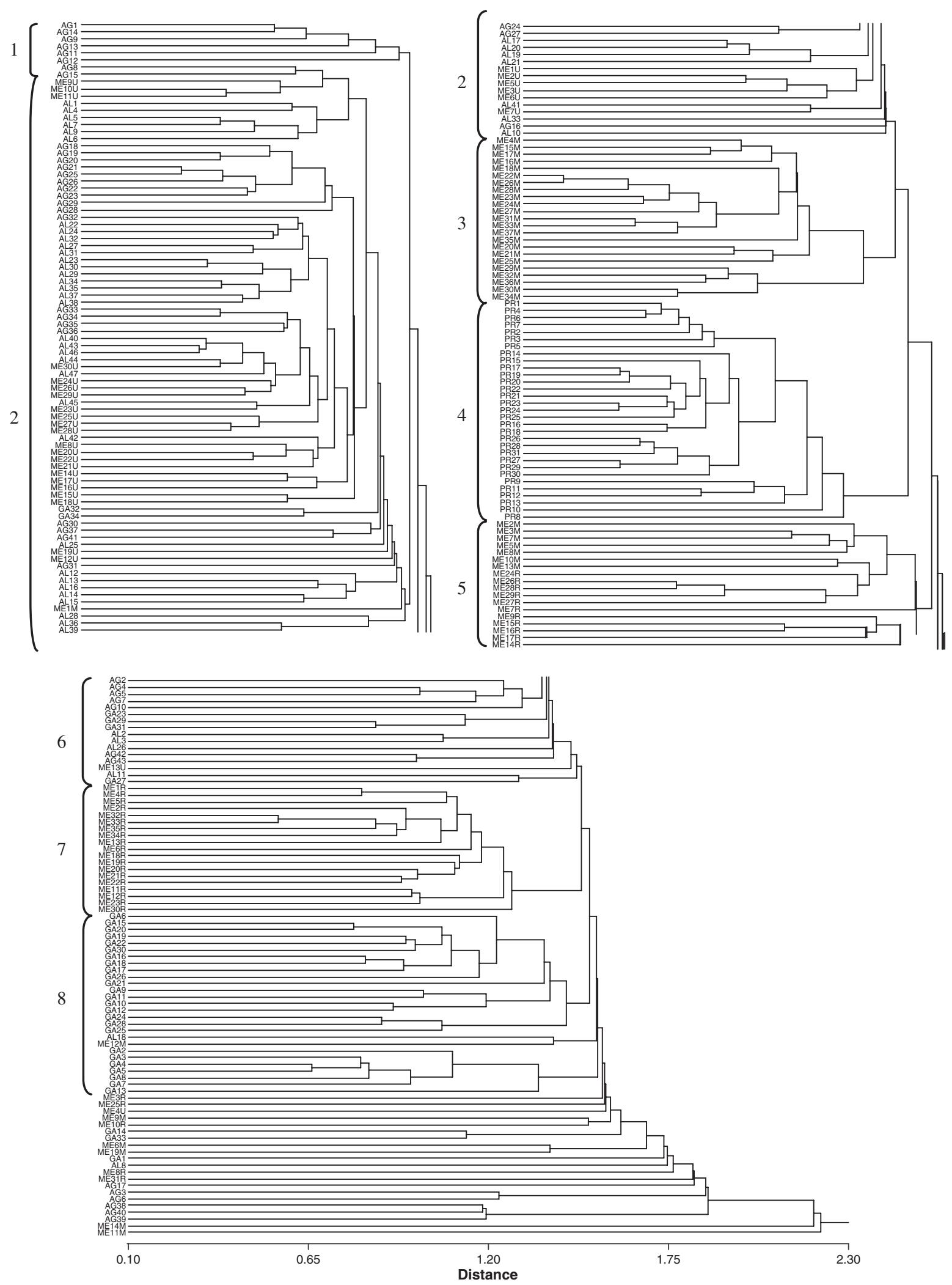

Figure 1 UPGMA-based phenogram based on 183 characters $\times 257$ cows belonging to five autochthonous cattle breeds from the southern region of Portugal (cophenetic correlation coefficient $r=0,88451$ ). Groups 1 to 8 are discussed in the text. 


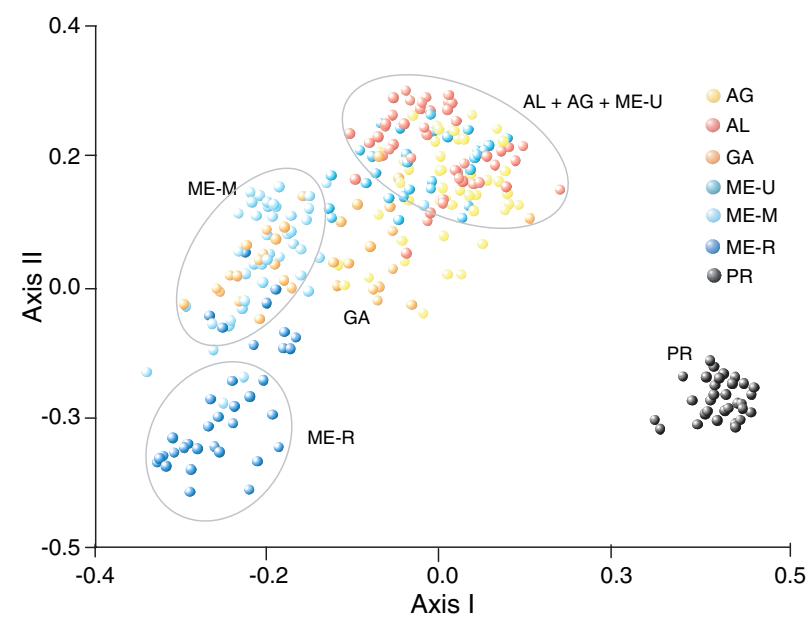

Figure 2 Projection of the 257 cows onto the plane defined by the first two principal coordinates.

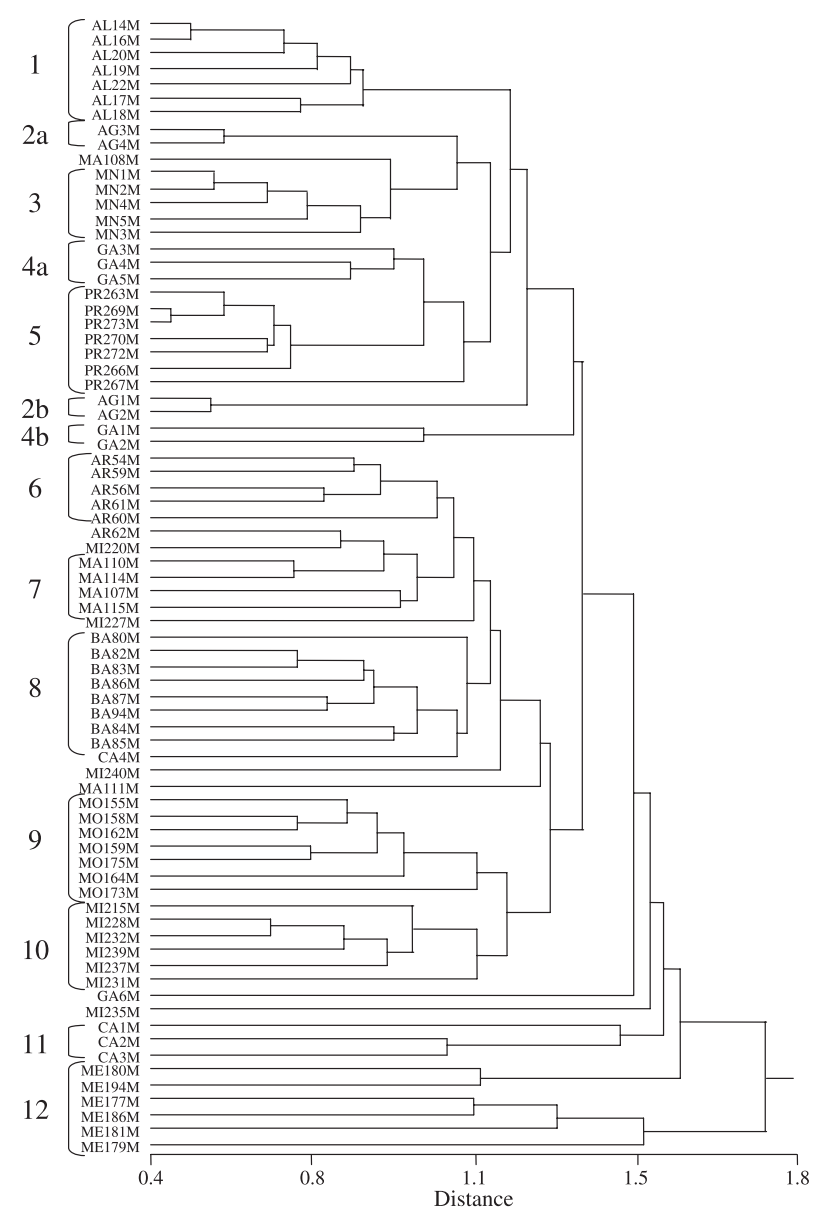

Figure 3 UPGMA-based phenogram of the 76 bulls belonging to twelve autochthonous breeds from Portugal $\times 170$ morphological characters (cophenetic correlation coefficient $r=0.84763$ ). Groups 1 to 12 are discussed in the text.

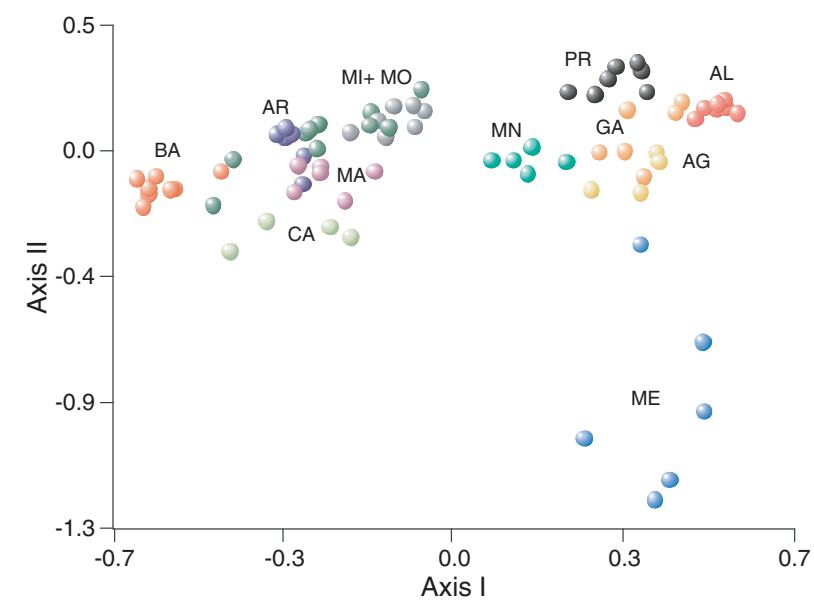

Figure 4 Projection of the 76 bulls onto the plane defined by the first two principal coordinates.

according to breed, with the highest morphological variability shown by ME bulls. The observed overlap between AR, MA, MO and MI individuals is consistent with their common origin (Vale, 1949; Cordeiro, 1986). The first two principal coordinates accounted for $45 \%$ of the variance.

The northern breeds (BA, CA, AR, MA, MI, MO and $\mathrm{MN}$ ) appeared separated from the southern ones (PR, GA, AG, ME and AL), with MN occupying an intermediate position. BA, CA, AR, MI, MA belong to the Brown Concave group, MO to the Iberian Black Orthoide group, and MN, GA, AG, ME and $\mathrm{AL}$, to the Red Convex group (Aquitanian trunk, Vale, 1949). PR belongs to the Iberian trunk, possibly derived from Brava de Lide, MI, AL and Spanish breeds from the Iberian Black group (IMAIAA, 1993). When a pairwise comparison was done for the breeds (as opposed to considering pairs of bulls) the average taxonomic distance was 1.02, the highest similarity was 0.64 (MA versus AR) and the lowest 1.39 (ME versus BA) (Table 1).

\section{Representative traits of $A G$}

The simultaneous projection of the morphological characters and of animals onto the two principal axes was used to find out which morphological traits are the best in discriminating the AG population. The AG animals are medium size (approximately $600 \mathrm{~kg}$ for cows, $800 \mathrm{~kg}$ for bulls), have a red coat colour and pink skin. Their heads are long and large, uniformly coloured with short hair, narrow forehead and long face. Their profile is convex; with the eyes, positioned in the upper part of the skull having prominent eyeballs and the ears bearing short 
Table 1 Matrix $R_{\mathrm{MT}}$ of distance coefficients for 12 autochthonous Portuguese breeds based on variation at 170 characters (170 characters $\times 12$ breeds). Each of the 170 characters values represents the mean across all bulls within a breed. The highest and lowest values, in bold, are discussed in the text.

\begin{tabular}{|c|c|c|c|c|c|c|c|c|c|c|c|c|}
\hline & $A G$ & $\mathrm{AL}$ & AR & BA & CA & GA & MA & MO & ME & $\mathrm{MN}$ & MI & PR \\
\hline Algarvia (AG) & 0.00 & & & & & & & & & & & \\
\hline Alentejana (AL) & 0.90 & 0.00 & & & & & & & & & & \\
\hline Arouquesa (AR) & 1.08 & 1.10 & 0.00 & & & & & & & & & \\
\hline Barrosã (BA) & 1.21 & 1.32 & 0.70 & 0.00 & & & & & & & & \\
\hline Cachena (CA) & 1.16 & 1.32 & 0.97 & 0.94 & 0.00 & & & & & & & \\
\hline Garvonesa (GA) & 0.85 & 0.90 & 1.03 & 1.18 & 1.13 & 0.00 & & & & & & \\
\hline Marinhoa (MA) & 1.02 & 1.13 & 0.64 & 0.77 & 0.97 & 0.99 & 0.00 & & & & & \\
\hline Maronesa (MO) & 1.06 & 1.03 & 0.74 & 0.88 & 0.99 & 0.95 & 0.88 & 0.00 & & & & \\
\hline Mertolenga (ME) & 1.18 & 1.26 & 1.29 & 1.39 & 1.30 & 1.17 & 1.24 & 1.24 & 0.00 & & & \\
\hline Minhota (MN) & 0.86 & 0.99 & 0.85 & 1.08 & 1.06 & 0.85 & 0.79 & 0.94 & 1.19 & 0.00 & & \\
\hline Mirandesa (MI) & 1.12 & 1.13 & 0.77 & 0.91 & 0.98 & 1.00 & 0.83 & 0.72 & 1.28 & 0.97 & 0.00 & \\
\hline Preta (PR) & 1.01 & 0.99 & 0.98 & 1.21 & 1.24 & 0.74 & 1.00 & 0.85 & 1.27 & 0.93 & 1.03 & 0.00 \\
\hline
\end{tabular}

internal hairs. The horns are long, point backwards and outwards from their midpoint, and are unevenly pigmented. The neck is thick and the dewlap large. The wide back has a long leaning croup, with a dorsal line rising towards the hindquarters (saddle shape). The rear legs are covered with hair, more pigmented towards the hock. The hooves are dark, the tail long and inserted upwards with light coloured hair and the udder white speckled with insertion at right angle.

\section{Discussion}

Breed conservation involves an assessment of state of diversity and the cultural and economic importance of the breed. To decide whether a breed is suitable for conservation purposes, objective criteria need to be applied to evaluate variability, because the cost of implementation is not trivial. Loss of diversity per se should not be neglected, since diversity will be critical in the face of environmental change and natural resources depletion.

Before investing in a diversity analysis based on DNA fingerprinting, we exploited a large set of morphological traits to define a group of animals representative of the AG breed. The distinctive morphology of the AG breed, as described by Pereira (1960) consists of a red to gold-yellow pelage, pyramidal head, a slight convex profile, separated eyeballs, in general short, spiral, outward-pointing horns, mucosa with coloured circles, a thick neck of intermediate length, large slack dewlap, a well-muscled shoulder tightly attached to the neck and back; a long, well-muscled, round and somewhat sloping croup, a roundish and ample back, a thick and long tail, high inserted, a well developed but not very bulky udder with separated teats, which are lighter coloured than the pelage, pale toes. The phenotypic description as given by traditional breeders largely coincided with these traits, apart from the gold yellow pelage described by Pereira (1960) for some animals, the shorter horns (longer in the current sample of animals), the separated and uniformly coloured teats (as opposed to being inserted at right angle and speckled), and the pale (as opposed to dark) colour of the toes. Although accurate weight data have not been provided by Pereira (1960) the indication is that the bulls were smaller than what we have classified as 'medium size' in our sample. The apparent increase in size over time probably reflects the outcome of several decades of selection pressure to improve meat production. These traits were used for the identification of animals with AG ancestry. However, an additional comparative study for Portuguese native cattle using morphological traits was required to assess the degree of differentiation of the AG breed.

Some morphological traits are heavily influenced by selection, and these are particularly important for the definition of a breed. Morphology can nevertheless illuminate the evolutionary history of domestic animals, especially for traits with little non-genetic variation and for traits which have not been subjected to artificial selection. The variation present in 24 bulls from eight Portuguese breeds with respect to 135 morphological characters was reported earlier by Sobral et al. (2001). The present study was based on additional individuals from these, and from four other breeds, as well as additional data from cows and more morphological characters. We have shown that cows can be used for breed differentiation, provided that the morphological characters have been 
carefully chosen. The general lesser expression of traits in cows was counterbalanced by a higher number of analysed characters, namely in udder and teats.

The average morphological distance coefficients between Portuguese cattle breeds were higher than those presented by Jordana et al. (1991) for Spanish breeds (1.02 among 12 versus 0.57 among 20). This difference, however, probably reflects the higher total number of characters and the higher proportion of head characters analysed in the present study.

The Portuguese cattle breeds can be separated along geographical and ethnic lines. This made it possible to identify a group of morphologically distinct animals with AG ancestry. The AG population is phenotypically similar to other breeds within the Red Convex group, including MN from the northern region of Portugal, close to Galicia (Spain). AG and GA are considered to be descended from AL (Vale, 1949), and the present cluster analysis classified AG as being very similar to AL. Some of the AG animals (AG2, AG4, AG5, AG7, AG10, AG42, and AG43) clustered with GA and AL. The ME breed is phenotypically very variable, including three distinct subtypes based on coat colour. The morphological analyses confirmed this heterogeneity, and showed further that AG animals are similar to the uniform red coat colour ME subtype. Six cows classified as AG remained unclustered (Figure 1), and three of these (AG38, AG39 and AG40) formed a distinct group in an additional principal coordinate analysis of the 43 cows (not shown).

The clustering patterns of the bulls and cows were not identical to one another (compare Figures 1 and $3)$. The clusters were better defined for the bulls, probably because the male morphological traits are more marked, thus allowing for a stronger level of distinction between the breeds. The ME bulls cluster in distinct small groups, although this may be an artefact of the small sample size (smaller than that of the cows) comprising different subtypes. In general, cows grouped into sub-clusters more frequently than did bulls, perhaps because of a tendency for inbreeding within the farm where a subgroup originated. Overall, the analyses suggest that a core group for further studies can be constructed from some of the AG cows in groups 1 and 2 (AGl, AG8, AG9, AGll, AG12, AGl3, AGl4, AGl5, AGl8, AG19, AG20, AG21, AG22, AG23, AG25, AG26, AG28, AG 29, AG 32) together with the four bulls AG1M, AG2M, AG3M and AG4M.

We have demonstrated that a quantitative analysis, based on 170 (bulls) and 183 (cows) morphologi- cal characters can provide a meaningful preliminary evaluation of animals thought to have AG ancestry. It has allowed for the identification of a core set of AG animals, on which a detailed DNA fingerprinting analysis can now be carried out to confirm and more accurately define a nuclear group for the recovery of the AG breed.

\section{Acknowledgements}

This research was funded in part by DGV-PIDDAC (Direcção Geral de Veterinária-Programa de Investimentos e Despesas de Desenvolvimento da Administração Central).

\section{References}

Alderson L. (1992) Categorisation of types and breeds of cattle in Europe. Arch. Zootec., 41, 325-334.

Cordeiro J.P. (1986) As raças bovinas em Portugal. Sua origem.. O Médico Veterinário, 1, 29-39.

FAO (2000) World Watch List for Domestic Animal Diversity. 3rd edn. Food and Agriculture Organisation of the United Nations, Rome.

Gower J.C. (1966) Some distance properties of latent root and vector methods used in multivariate analysis. Biometrika, 53, 325-338.

IMAIAA (1993) Anuário Pecuário 93. In: Instituto dos Mercados Agrícolas e Indústria Agro-Alimentar, Ministério da Agricultura, Lisboa.

Jordana J., Pelegrín M., Piedrafita J. (1991) Relaciones genéticas en bovinos españoles obtenidas a partir del estudio de caracteres morfológicos. Información Tecnica Economica Agraria, 87A, 50-64.

Lima S.B.. (1873) Recenseamento Geral de Gados no Continente do Reino de Portugal em 1870. Imprensa Nacional, Lisboa, pp. 1-246.

Lima S.B. (1919) Os escritos de Silvestre Bernardo Lima. Bovídeos e Suídeos. Boletim do Ministério da Agricultura; Direcção da Instrução Agrícola, Ano I 7, 1-266.

Matos C.A.P., (2000). Situação actual dos recursos genéticos animais em Portugal. Communication in II Congresso Ibérico sobre Recursos Genéticos Animais; Estação Zootécnica Nacional, Vale de Santarém.

Nogueira J.V.P.. (1900) Les animaux agricoles. In: B.C. Costa, L Castro. (Coord.), Le Portugal au Point de Vue Agricole. Imprimerie Nationale, Lisbonne, pp. 184-310.

Pereira M.T. (1960) A raça bovina Algarvia. Boletim Pecuário; Direcção Geral dos Serviços Pecuários, Ano XXVIII, 1, 137-189.

Rohlf F.J. (1998) NTSYS-pc, Numerical Taxonomy and Multivariate Analysis, version 2.0 Exeter Software. Setauket, New York. 
Rosado J., Almeida J.M., Gouveia J.M., Sobral M., Lobo J.M.S.. (1981) Raça bovina Algarvia. Inquérito para a sua caracterização e seu sistema de exploração. In: A Rodrigues. (Coord.), Bovinos em Portugal, Direcção Geral dos Serviços Veterinários, Lisboa, pp. 217-222.

Sneath P.H.A., Sokal R.R.. (1973) Numerical Taxonomy, The Principles and Practice of Numerical Classification. W. H. Freeman and Co, San Francisco, CA.

Sobral M.F., Cravador A., Navas D., Roberto C., Reis C., Lima M.B.. (2001) Classificação e caracterização mor- fológica de raças bovinas autóctones nacionais, utilizando a taxonomia numérica. Revista Portuguesa de Zootecnia, 2, 123-137.

Sokal R.R., (1961) Distance as a measure of taxonomic similarity. Syst. Zool., 10, 70-79.

Vale J.M.. (1949) Bovinos. O Homem e a Terra, Gado Bissulco. Suínos. Bovinos. Arietinos. Caprinos, Colecção de Livros Agrícolas, $4^{a}$ secção - A Exploração e a Criação de Animais - n 2, Lisboa, pp. 81-168. 